\title{
A CARTOGRAFIA TÁTIL NO ESTUDO DO LUGAR: FEIRA DE SANTANA
}

\author{
Juliana Oliveira dos Santos ${ }^{1}$ \\ Paula Daiane Araújo ${ }^{2}$ \\ Solange Lucas Ribeiro ${ }^{3}$
}

PALAVRAS-CHAVE- Lugar. Cartografia Tátil. Material Didático.

\section{INTRODUÇÃO}

No mundo globalizado, as informações chegam simultaneamente a diversos lugares do planeta, sobretudo através do desenvolvimento de novas tecnologias da informação e comunicação. Assim, compreender as inter-relações pessoais marcadas pela mundialização das informações, gostos, cultura, música, estilos de vida, entre outros, torna-se a cada dia mais complexo. E essa mundialização tem impactado diretamente as relações interpessoais em muitos lugares, visto que esse fenômeno tem contribuído para a homogeneização dos costumes e, consequentemente, causando estranheza das pessoas, devido a modificações em práticas cotidianas históricas.

Com a inserção de novas referências sociais, as relações cotidianas estabelecidas no lugar tornam-se mais frágeis, fazendo com que muitas pessoas tenham dificuldades de distinguir sua identidade de outras e reconhecer-se no seu lugar de vivência.

Entender as relações sociais num mundo altamente globalizado e competitivo é um desafio. Nesse ponto a escola é fundamental, pois é através de seu papel social de educar visando uma educação emancipatória, libertadora e a formação de um sujeito crítico e reflexivo, que lhe permitirá problematizar, analisar e entender a dinâmica enfrentada por diversos lugares. Além disso, cabe à escola a função de debater com os educandos que entender o lugar significa analisar o processo pelo qual passam através de uma visão sistêmica, já que há uma relação dialética entre questões políticas, econômicas e significações sociais ali materializadas, tendo em vista que essas relações globais estão em constante transformação.

A escola, portanto, deve intensificar sua prática no lugar para entender as variáveis internas e externas, buscando entender a realidade dos sujeitos com os quais lida. É importante que a instituição conheça a cultura e, além disso, participe do processo de mediação dessas informações exógenas e endógenas, pois conforme Chaveiro (2008), fechar-se no lugar pode significar apenas servir a um autoritarismo da tradição; e o extremo, abrir-se ao "fora" e às suas representações, pode ser o vínculo, apenas, ao que aliena e usa o lugar.

O conhecimento do lugar possibilitará aos educandos entender a realidade global e relacioná-la com a local e, também, discutir essas transformações no sentido de reconstruir e/ou reafirmar as referências e a identidade do lugar.

No campo educacional, a geografia é uma aliada importante na reafirmação da identidade, principalmente quando pautada na construção de saberes ligados à realidade socioespacial dos educandos e quando comprometida com o processo de construção do raciocínio geográfico, como salienta Cavalcanti (1998).

Em Feira de Santana, cidade em análise, é grande a escassez de referências teóricas e materiais didáticos para se trabalhar o estudo do lugar. Isso impacta diretamente na prática docente, fator que leva ao desconhecimento da história do lugar

\footnotetext{
1 - Bolsista FAPESB- Graduada em Geografia, Universidade Estadual de Feira de Santana-BA.

2 -Graduada em Geografia, Universidade Estadual de Feira de Santana-BA.

3. Orientadora, Departamento de Educação, Universidade Estadual de Feira de Santana-BA.
} 
pelo alunado. Se for notória a pouca disponibilidade de material didático, a questão acentua-se ainda mais quando nos referimos a materiais para o estudo do lugar direcionados aos alunos com deficiência, pelo fato desse público ser historicamente excluído do convívio social e educacional.

Diante desta realidade, é necessário construir e sistematizar esse conhecimento visando à escolarização dos alunos com deficiência, porque em tempos de inclusão, é inadmissível um currículo estático e tradicional que desconsidera as especificidades e as potencialidades de todos os sujeitos. Nesse sentido, a Tecnologia Assistiva (TA), é um importante instrumento para escolarização dos sujeitos, sendo a TA:

Uma área do conhecimento, de característica interdisciplinar, que engloba produtos, recursos, metodologias, estratégias, práticas e serviços que objetivam promover a funcionalidade, relacionada à atividade e participação de pessoas com deficiência, incapacidades ou mobilidade reduzida, visando sua autonomia, independência, qualidade de vida $\mathbf{e}$ inclusão social. (CAT, 2007c, apud, GALVÃO FILHO, 2009, grifo nosso).

Trabalhar a cartografia é um desafio para professores e alunos, sobretudo quando nos referimos a estudantes com deficiência visual, pois pela falta do sentido visual, acaba sendo retirado o seu direito de aprendê-la.

A Cartografia Tátil é um recurso de tecnologia assistiva muito relevante na mediação pedagógica de alunos com Deficiência Visual (DV). Os recursos táteis têm a vantagem de serem produzidos com baixo custo financeiro e visam proporcionar ao aluno com deficiência visual mais autonomia, mobilidade e aprendizagem do conhecimento geográfico, aspecto muito importante no mundo globalizado, que exige dos sujeitos, cada vez mais, o entendimento da dinâmica que o cerca. Por isso deve ser estudada, divulgada e incentivada.

A Cartografia Tátil é:

[...] um ramo específico da cartografia, que se ocupa da confecção de mapas e outros produtos cartográficos, para serem usados por pessoas cegas ou com baixa visão. Eles podem ter objetivos educativos e/ou serem facilitadores da orientação e mobilidade dessas pessoas nos espaços de vivência. (RIBEIRO, 2012, p.96, grifo nosso).

Assim, esse trabalho teve como objetivo estudar o lugar (Feira de Santana), bem como elaborar metodologias e materiais didáticos táteis .O trabalho se justifica pela carência de referenciais teóricos e materiais nessa área, além de valorizar as experiências e anseios dos pesquisados, tornando os recursos confeccionados mais eficientes, pois serão testados e imediatamente analisados pelos seus usuários diretos, permitindo aperfeiçoá-los de modo a torná-los operacionais, de acordo com as singularidades dos sujeitos. Também proporcionará ao professor desenvolver um olhar reflexivo de sua prática no sentido de transformá-la e melhorá-la (PIMENTA e GHEDIN, 2006).

\section{METODOLOGIA}

O trabalho foi realizado utilizando-se a pesquisa-ação, também conhecida como pesquisa colaborativa, que surge como alternativa ao engendramento de estudos emancipatórios, "no âmbito da educação, atividade de co-produção de saberes, de formação, reflexão e desenvolvimento profissional, realizada interativamente por pesquisadores e professores com o objetivo de transformar determinada realidade educativa" (IBIAPINA, p.31, 2008).

Para tanto, a revisão bibliográfica foi importantíssima para estruturar o arcabouço teórico sobre o lugar (Feira de Santana), bem como o conhecimento pertinente à educação inclusiva. 
Posteriormente, realizou-se entrevista com professores das escolas campo da pesquisa, para identificar e analisar as dificuldades dos mesmos em trabalharem a cartografia e os conteúdos relativos à Feira de Santana para alunos com deficiência visual.

Foram sujeitos da pesquisa 15 professores de Salas de Recursos Multifuncionais (de escolas distintas) da rede municipal de Feira de Santana. Os instrumentos foram questionários, entrevista e oficinas.

Foi realizada uma oficina, com esses professores, após uma preparação teórica referente à educação inclusiva e os princípios da cartografia tátil depois procederam à confecção dos recursos táteis, considerando a análise qualitativa dos dados.

\section{ANÁLISE E DISCUSSÃO DOS RESULTADOS}

Os dados contidos nos questionários atestam que, das 15 escolas pesquisadas, apenas seis possuem recursos. Além disso, dessas escolas que possuem os recursos táteis, cerca de $73 \%$ dos professores não os utilizam na mediação com os alunos cegos nas SRM.

Outro dado relevante é que a maioria dos professores de geografia não solicita recursos táteis para trabalhar na sala de aula regular, possivelmente, isso é um reflexo da falta de conhecimento tanto dos professores das Salas de Recursos Multifuncionais quanto da sala regular, sobre as potencialidades dessa ferramenta. Além disso, para que os professores das Salas de Recursos Multifuncionais façam um material que de fato atenda as especificidades dos alunos, é necessária a articulação entre esses dois profissionais, desde o planejamento da atividade até ao pós execução, pois o professor de geografia é que detém o conhecimento dos princípios da cartografia convencional, esse conhecimento levará ao entendimento de como se estrutura a Cartografia Tátil. Nesse sentido, identificou-se a total desarticulação entre esses profissionais.

Um dado preocupante apontado pelos questionários foi à alegação dos professores de que a falta dos recursos se devia ao desconhecimento e, pelo fato da escola não ter aluno deficiente visual, naquele momento. Apesar de todos os contrapontos $80 \%$ dos entrevistados falaram que gostariam de confeccionar recursos cartográficos táteis sobre Feira de Santana e o país. Por conta disso, foram desenvolvidas oficinas para construção dos recursos, mostrados a seguir.
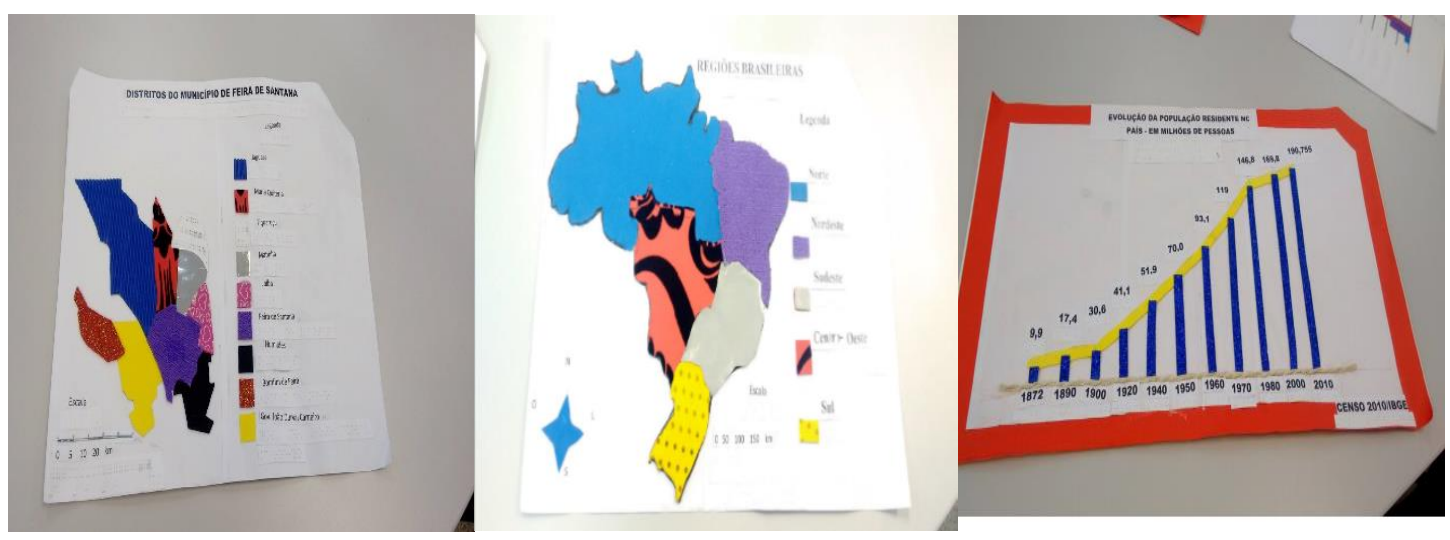


\section{CONSIDERAÇÕES FINAIS}

A produção teórica e, consequentemente, o estudo do lugar é muito incipiente no município de Feira de Santana, levando ao esquecimento e ao não-conhecimento da história e características físicas e econômicas do referido município. Isso impacta diretamente nas relações das pessoas com o seu cotidiano, sobretudo por vivenciarmos o fenômeno da globalização, no qual as informações, gostos e cultura adentram vários lugares causando estranheza em relação ao lugar de vivencia. Por isso, é importantíssimo a atuação da escola para entender e mediar o convívio com esse fenômeno que acontece no lugar de vivencia de seus educandos.

A atuação educacional se faz ainda mais necessária quando falamos de pessoas com Necessidade Educacionais Especiais, por isso a criação de um ambiente que favoreça o ensino-aprendizagem é imperioso. No cenário inclusivo, a cartografia tátil emerge como instrumento fundamental para o letramento cartográfico de estudantes com deficiência visual.

Nesse sentido, conclui-se que o trabalho é de suma relevância para o fortalecimento do estudo do lugar (Feira de Santana) e das premissas da educação inclusiva, já que se conseguiu identificar e analisar as dificuldades dos professores em trabalhar a cartografia com alunos com deficiências visuais; a existência e a frequência de uso dos recursos táteis sobre feira de Santana e outros e de trabalhar de forma colaborativa visando atender as suas necessidades. Além disso, os dados obtidos poderão embasar outras pesquisas.

\section{REFERÊECIAS:}

CAVALCANTI, Lana de Souza. Geografia, Escola e Construção de Conhecimentos. Campinas/SP: Papirus, 1998.

CHAVEIRO, Eguimar Felício. O cerrado em disputa: sentidos culturais e práticas sociais contemporâneas. In: Maria Geralda de Almeida; Eguimar Felício Chaveiro; Helaine Costa Braga. (Org.). Geografia e Cultura - os lugares da vida e a vida dos lugares. 1 ed. Goiânia - Goiás: Editora Vieira, 2008, v. 1, p. 75-97.

GALVÃO FILHO, Teófilo Alves. Tecnologia Assistiva para uma escola inclusiva: apropriação, demandas e perspectivas. Tese (Doutorado em Educação) Faculdade de Educação, Universidade Federal da Bahia (UFBA), Salvador, 2009.

IBIAPINA, Ivana Lopes de Melo. Pesquisa colaborativa: investigação, formação e produção de conhecimentos. Brasília: Líber Livro Editora 2008.

PIMENTA. Selma Garrido e GHEDIN, Evandro (Orgs.). Professor reflexivo no Brasil: gênese e crítica de um conceito. São Paulo: Cortez, 2006.

RIBEIRO, Solange Lucas. A interface Educação Geográfica e Inclusão de Alunos com Deficiência Visual: possíveis contribuições para representar e desvendar o espaço. In: PORTUGAL, J. F.; CHAIGAR, V. A. M. Cartografia, Cinema, Literatura e outras Linguagens no Ensino de Geografia. Curitiba, PR: CVR, 2012. 